J. Clin. Chem. Clin. Biochem.

Vol. 20, 1982, pp. $807-812$

\title{
A Procedure for the Determination of High-Density Lipoprotein Choline-Containing Phospholipids ${ }^{1}$ )
}

\author{
By M. W. McGowan \\ Department of Biochemistry
}

\section{J. D. Artiss}

Department of Pathology and

\section{B. Zak}

\section{Departments of Biochemistry and Pathology}

\author{
Wayne State University School of Medicine and the Detroit Receiving Hospital/University Health Center, \\ Detroit, MI, U.S.A.
}

(Received March 3/August 16, 1982)

Summary: A procedure for the determination of serum high-density lipoprotein choline-containing phospholipids is described. The choline-containing phospholipids represent $91-97 \%$ of the total serum and high-density lipoprotein phospholipids, which have previously been determined in relation to liver disease, neoplastic disorders, diabetes mellitus and atherosclerosis. The enzymatic assay is quick, simple and precise. No interference was found from the precipitating agents used to isolate the high-density lipoprotein fraction. Several serum samples were assayed for high-density lipoprotein cholesterol and choline-containing phospholipids. From this preliminary data there would appear to be a correlation between these two lipid classes.

\section{Bestimmung der Cholin enthaltenden Phospholipide in High Density Lipoproteinen}

Zusammenfassung: Ein Verfahren zur Bestimmung der Cholin enthaltenden Phospholipide in High Density Lipoproteinen des Serums wir beschrieben. Die Cholin enthaltenden Phospholipide machen 91-97\% der gesamten Phospholipide in Serum und High Density Lipoproteinen aus. Phospholipide wurden bereits früher in Zusammenhang mit Lebererkrankungen, Neoplasien, Diabetes mellitus und Arteriosklerose bestimmt.

Die enzymatische Bestimmung ist schnell, einfach und zuverlässig. Fällungsreagenzien zur Isolierung der High Density Lipoprotein-Fraktion stören die Bestimmung nicht. Zahlreiche Serumproben wurden auf High Density LipoproteinCholesterin und Cholin enthaltende Phospholipide untersucht. Aufgrund dieser vorläufigen Ergebnisse scheint eine Korrelation zwischen dièsen beiden Lipidklassen zu bestehen.

\section{Introduction}

The determination of total serum phospholipids has previously been performed in the study of several disease states, primarily for research purposes. They are usually determined by chemical digestion of the organic portion of the phospholipids followed by phosphate determination. Total serum phospholipids have been measured in relation to extrahepatic obstruction (1), certain neoplastic disorders (2), diabetes mellitus (3) and atherosclerosis $(3,4)$.

1) Supported in part by a Grant-in-Aid from the Michigan Heart Association, Citation Clinical Laboratories, Ltd., Southfield, $\mathrm{MI}$ and the Detroit Receiving Hospital Research Corporation.
The determination of serum high-density lipoprotein (HDL) cholesterol has become a widely used test for assessing the predisposition to coronary heart disease since HDL cholesterol levels have been shown to be inversely related to the risk of developing coronary heart disease (5). There may also be a relationship between serum HDL-choline-containing phospholipids and the risk of developing coronary heart disease, due to the role of phospholipids in lipoproteins. Phospholipids have been reported to stabilize lipoproteins and may be necessary for the binding of cholesterol and its esters to the lipoproteins $(6,7)$.

A method for the determination of total serum cholinecontaining phospholipids has been previously described 
(8). This procedure utilized phospholipase D from Streptomyces chromofuscus to hydrolyze choline from phosphatidylcholine, lysophosphatidylcholine and sphingomyelin. It is of note that not all phospholipids contain choline. However, those that do comprise 91$97 \%$ of the total phospholipids found in serum $(9,10)$. Choline oxidase was then used to generate hydrogen peroxide from the choline, and the hydrogen peroxide was in turn utilized in the peroxidase catalyzed oxidative coupling of 4-aminoantipyrine and phenol to form a red quinonimine chromogen. This procedure has since been applied to the determination of HDL choline-containing phospholipids $(3,11-13)$. Since the amount of choline-containing phospholipids in the serum HDL fraction is typically only $48 \%$ of the total serum cholinecontaining phospholipids (9) the original procedure was modified to increase its sensitivity by the substitution of sodium 2-hydroxy-3,5-dichlorobenzenesulfonate for phenol in the peroxidase-catalyzed indicator reaction. This type of modification has been used previously in procedures for the determination of HDL cholesterol (14) and choline-containing phospholipids in amniotic fluid (15). The use of 2-hydroxy-3,5-dichlorobenzenesulfonate has been shown to produce a several-fold increase in sensitivity over that of phenol (14) thus . facilitating a marked improvement in the sensitivity and precision of lipid determinations.

In the present report the characteristics of this procedure are described including the possible interfering effects of the precipitating reagents that were used previously in an HDL cholesterol procedure (14). This precipitating reagent has previously been compared with several other precipitating agents for possible interfering effects in an enzymatic HDL cholesterol assay (16). Finally, this procedure for HDL choline-containing phospholipids is used in a preliminary investigation into the possible correlation between serum HDL cholesterol and HDL choline-containing phospholipids. To this end, several serum samples, ranging widely in total cholesterol concentrations, were assayed for both HDL cholesterol and choline-containing phospholipids and the degree of correlation between them was determined.

\section{Materials and Methods}

Tris-hydrochloride was obtained from Research Plus Laboratories, Inc. (Denville, N.J. 07834). Triton X-100, magnesium acetate, 4-aminoantipyrine, $L$ - $\alpha$-phosphatidylcholine (dipalmitoyl, synthetic) and peroxidase (from horseradish; hydrogen-peroxide oxidoreductase, EC 1.11.1.7) were obtained from Sigma Chemical Co. (St. Louis, MO 63178). Calcium chloride dihydrate was obtained from Mallinckrodt Inc. (St. Louis, MO 63134). Choline oxidase (from Arthrobacter globiformis; choline: oxygen 1-oxidoreductase; EC 1.1.3.17) and phospholipase D (from Streptomyces chromofuscus; phosphatidylcholine phosphatidohydrolase; EC 3.1.4.4) were obtained from Fermco Biochemics, Inc. (Elk Grove Village, IL 60007). Sodium 2-hydroxy-3,5-dichlorobenzenesulfonate was obtained either from Research Organics, Inc. (Cleveland, OH 44125 ) or Biosynth International (Skokie, IL 60077 ) or was prepared as previously described $(15,17)$.
Sodium dextran sulfate 500 was obtained from Pharmacia Fine Chemicals, Inc. (Piscataway, Nj 08854). Choline chloride was obtained from Eastman Organic Chemicals (Rochester, NY 14650). The enzymatic cholesterol reagent without phenol was generously supplied by Dr. Carol Cox of Abbott Laboratories (Diagnostics Division, South Pasadena CA 91030). The chemical composition of this reagent has been previously described (14). Cholesterol standards were also obtained from Abbott Laboratories.

All spectrophotometric work was performed on either a Beckman Model 25 Spectrophotometer (Beckman Instruments, Fullerton, CA 92634), or a Gilford Model 300N Spectrophotometer (Gilford Instrument Laboratories, Inc., Oberlin, OH 44074).

\section{Reagents}

Stock phospholipid reagent: Prepare a Tris- $\mathrm{HCl}$ buffer, $50 \mathrm{mmol} / \mathrm{l}$, pH 7.8, to contain $2 \mathrm{~g} / 1$ Triton X-100, $2.9 \mathrm{mmol} / 1$ 4-aminoantipyrine and $500 \mu \mathrm{mol} / 1 \mathrm{CaCl}_{2} \cdot 2 \mathrm{H}_{2} \mathrm{O}$. Storied at $4{ }^{\circ} \mathrm{C}$ thị reagent is stable for at least one month.

Working phospholipid reagent: Preparie this reagent to contain $1 \mathrm{kU} / 1$ phospholipase $\mathrm{D}, 1 \mathrm{kU} / 1$ choline oxidase and $10 \mathrm{kU} / 1$ peroxidase in the above stock phospholipid reagent. Stored at $4{ }^{\circ} \mathrm{C}$ this reagent is stable for about 3 days.

Sodium 2-hydroxy-3,5-dichlorobenzenesulfonate reagent: Prepare a Tris-HCl buffer, $50 \mathrm{mmol} / \mathrm{l}$, $\mathrm{pH} 7.8$, to contain $2 \mathrm{~g} / 1$ Triton $\mathrm{X}=100$ and $154 \mathrm{mmol} / 1$ sodium 2-hydroxy-3,5-dichlorobenzenesulfonate. Stored at $4^{\circ} \mathrm{C}$ this reagent is stable for at least 1 month.

Lecithin standards: $L$ - $\alpha$-phosphatidylcholine (dipalmitoyl, synthetic) was dissolved in deionized water, coñtaining $5 \mathrm{~g} / 1$ Tritön $\mathrm{X}-100$, to a concentration of $3.0 \mathrm{mmol} / \mathrm{l}$. Serial dilutions of this standard were made with $5 \mathrm{~g} / 1$ Triton X-100 to contain $0 . \overline{5}, 1.0$, 1.5 and 2.0 mmol $/ 1$ lecithin.

Cholesterol reagent: Prepare this reagent by reconstitution of the previously described dry enzyme reagent (14) with deionized water containing 4-aminoantipyrine and 2-hydroxy-3,5-dichlorobenzenesulfonate to final concentrations of 2.4 and $9 \mathrm{mmol} / \mathrm{l}$, respectively.

Magnesium acetate: Prepare this reagent to contain $2 \mathrm{~mol} / \mathrm{l}$ magnesium acetate in deionized water.

Dextran sulfate 500: Prepare this reagent to contain $20 \mathrm{~g} / \mathrm{l}$ dextran sulfate 500 in deionized water.

All enzyme units quoted are used as defined by the suppliers.

Procedures

\section{Isolation of serum HDL fractions .}

To $1 \mathrm{ml}$ of serum add $50 \mu \mathrm{l}$ of dextran sulfate 500 solution and mix well. Subsequently $50 \mu \mathrm{l}$ of magnesium acetate solution was added and mixed well. This mixture was then allowed to stand at room temperature for $10 \mathrm{~min}$ followed by centrifugation at $1200 \mathrm{~g}$ for 15 min. After centrifugation the HDĹ-containing supernatant was transferred to a clean tube (18). Note that this procedure may be scaled down considerably.

\section{Determination of choline-containing phospholipids .}

The working phospholipid reagent was dispensed intō 1 mạl aliquots and incubated at $37^{\circ} \mathrm{C}$, for $3 \mathrm{~min}$. Upon completion of this preincubation $100 \mu$ lof the sodium 2-hydroxy $=3,5$-dichlorobenzenesulfonate reagent was added and mixed. It is possible to premix the 2-hydroxy-3,5-dichlorobenzenesulfonate and phospholipid reagents, however, the absorbance of the blank may increase significantly over the period of $1-3$ days. Consequently we chose to separate them in order to improve the shelf life of the reagents (i.e., prevent the air catalyzed oxidative coupling of the chromogen system). Ten microliters of sample or standard were added, mixed and incubated at $37^{\circ} \mathrm{C}$ for $12 \mathrm{~min}$. After incubation the absorbance was measured at $510 \mathrm{~nm}$ against a reagent blank, in which deionized water was substituted for sample or standard. 


\section{Determination of cholesterol}

Ten microliters of sample or standard were added and mixed with $1 \mathrm{ml}$ of the cholesterol reagent. After a $10 \mathrm{~min}$ incubation at $37^{\circ} \mathrm{C}$, the absorbance was measured at $510 \mathrm{~nm}$ against a reagent blank in which deionized water was substituted for the sample (14). The values obtained for HDL choline-containing phospholipids and HDL cholesterol were multiplied by 1.1 to correct for the dilution of sample due to the addition of the precipitating reagents.

\section{Results and Discussion}

Preliminary experiments were conducted in order to optimize the activities of the enzymes and the sample to reagent ratio for the choline-containing phospholipids procedure. Under the described reaction conditions the hydrolysis of the phospholipids, the oxidation of the choline and the coupling of the indicator reaction are complete within 10-15 min for the phospholipid concentrations commonly encountered in the HDL fraction of serum. As described, a 12 min incubation was used routinely with fresh reagent. However, it was found to be necessary to extend this incubation to $15 \mathrm{~min}$ for working phospholipid reagent that was 3 days old. Apart from the necessity of using a slightly longer incubation in order to reach equilibrium there were no apparent deleterious effects resulting from the use of 3 day old working phospholipid reagent. The time required to reach equilibrium may be checked by plotting a rise curve, as described in figure 1, using the high standard as a sample. It may be seen in figure 1 that equilibrium over the range of $1.0-3.0 \mathrm{mmol} / 1$ is reached within $15 \mathrm{~min}$.

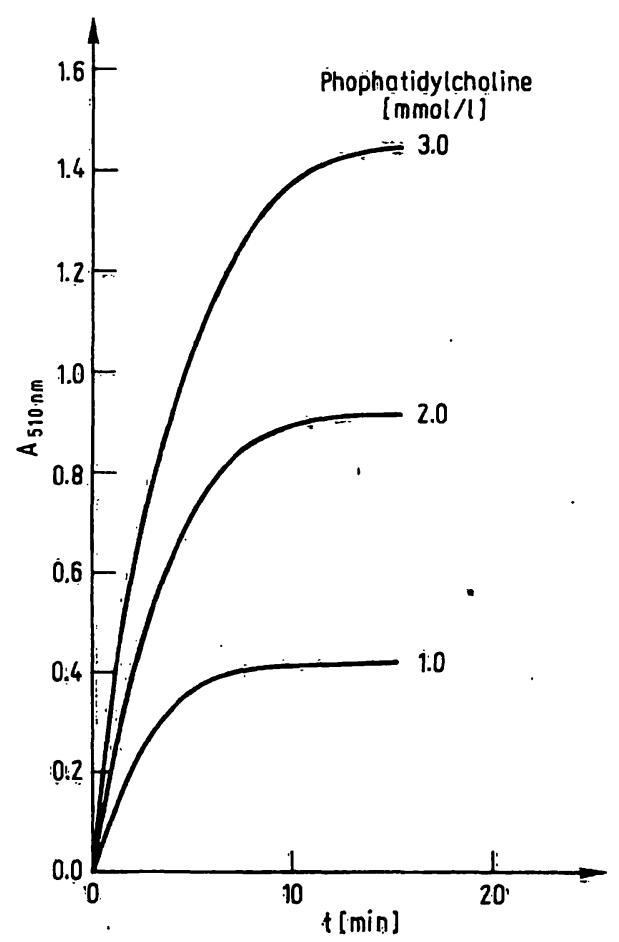

Fig. 1. Shown are representative rise curves at $37^{\circ} \mathrm{C}$ at $510 \mathrm{~nm}$, for three levels of phosphatidylcholine, 1.0, 2.0 and 3.0 $\mathrm{mmol} / \mathrm{l}$.
Takayama et al. (8) have demonstrated that under similar reaction conditions phospholipase D hydrolysis of the three different phospholipids is complete. We have previously reported (15) that if not complete that the degree of hydrolysis of the various phospholipids is constant and therefore does not present any appreciable problems.

The use of calcium as an activator for phospholipase D of microbial origin has been described previously (19). Although it has been reported (15) that it was not necessary to include calcium in the reagent, subsequent studies indicate that it is a necessary ingredient. Figure 2 depicts a plot of calcium concentration versus the rate of colour development for the assay. It may be seen that the activity increases markedly up to a calcium concentration of $0.1 \mathrm{mmol} / \mathrm{l}$ and then remains relatively constant to $1.0 \mathrm{mmol} / \mathrm{l}$. In order to allow considerable latitude in reagent preparation, $0.5 \mathrm{mmol} / 1$ calcium was chosen to be optimal.

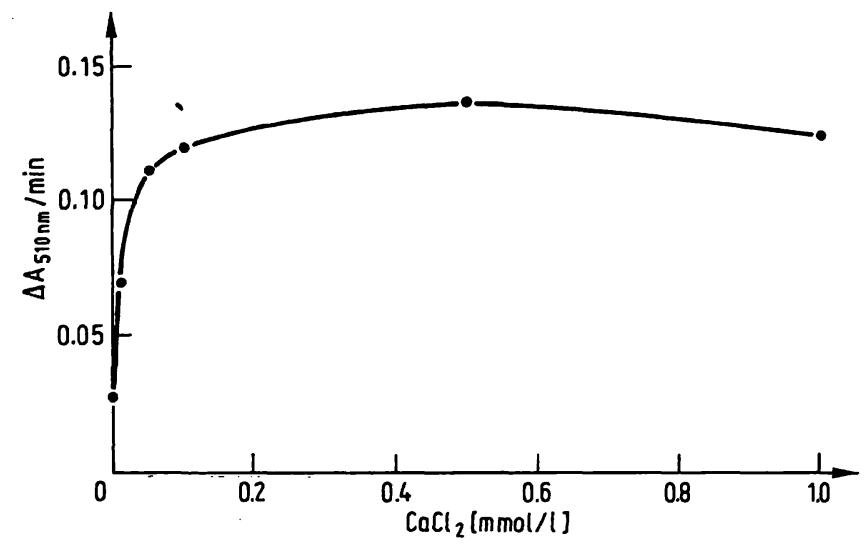

Fig. 2. Shown are the effects of calcium on the rate of colour development, at $510 \mathrm{~nm}$, with the choline-containing phospholipid assay.

As has been described previously Triton X-100 is included in the reagent as a solubilizer of reagents and samples (15) as well as an activator of microbial phospholipase D (19).

Unlike the phospholipase $D$ from cabbage which shows activity primarily towards phosphatidylcholine, the phospholipase $\mathrm{D}$ of microbial origin exhibits activity towards other phospholipids such as phosphatidylethanolamine as well as the other choline-containing phospholipids, lysophosphatidylcholine and sphingomyelin $(15,19)$. However, since choline oxidase is specific for choline and the intermediate betaine aldehyde (20), only the choline-containing phospholipids are measured in this procedure. Measuring only the choline-containing phospholipids still gives an accurate representation of the overall phospholipid level in serum, as the choline-containing phospholipids typically comprise something greater than $91 \%$ of the total serum phospholipids $(9,10)$. It is also of note that the cholinecontaining phospholipid content of the HDL fraction is similar to that of whole serum (9). 
The concentration of choline-containing phospholipids in this report is expressed in units of $\mathrm{mmol} / \mathrm{l}$ rather than $\mathrm{mg} / \mathrm{dl}$ due to the heterogeneity of the phospholipids. Phosphatidylcholine, lysophosphatidylcholine and sphingomyelin differ from each other in their basic structures as well as within their separate classes with regard to the degree of saturation and length of their fatty acid chain(s) (9). It would seem to follow that the choline-containing phospholipid concentration of serum should not be readily compared to the concentration of a homogeneous standard on a weight per unit volume basis. By using a synthetic phosphatidylcholine whose molecular weight is known, it is possible to relate the absorbance obtained to the number of moles of choline released, and therefore to the number of moles of choline-containing phospholipid in the sample.

In a previous report (14), the substitution of 2-hydroxy3,5-dichlorobenzenesulfonate for phenol in an enzymatic HDL cholesterol procedure was described. The substitution resulted in a 4.4 fold increase in sensitivity as well as an increase in the precision of the procedure. The enzymatic determination of choline-containing phospholipids is already inherently more sensitive than that of cholesterol, since the choline oxidase catalyzed oxidation of one mole of choline produces two moles of hydrogen peroxide while oxidation of one mole of cholesterol by cholesterol oxidase produces but one mole of hydrogen peroxide. This can be more easily seen in a plot of their respective standard curves (fig. 3).

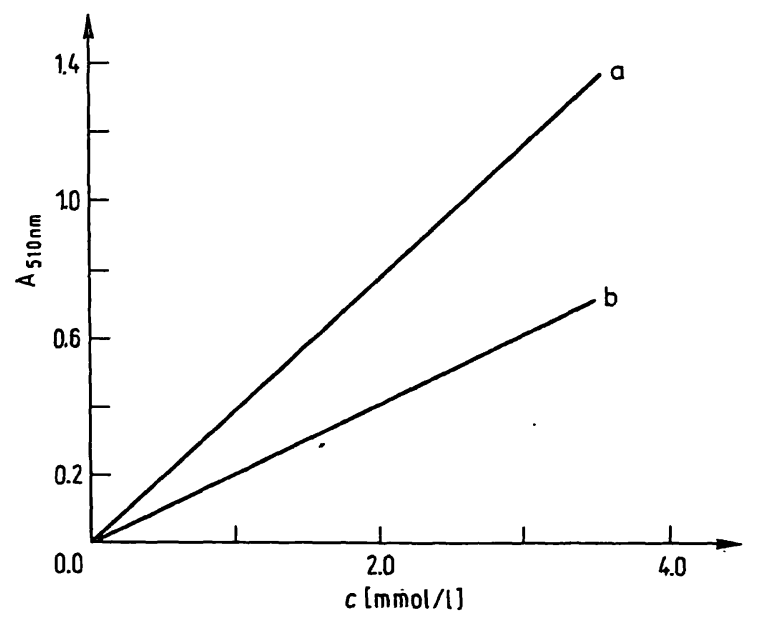

Fig. 3. Shown are representative standard curves, at $510 \mathrm{~nm}$, for choline $(a ; m=0.478)$ and cholesterol $(b ; m=0.262)$ utilizing the same indicator reaction.

These curves were obtained with equimolar amounts of choline and cholesterol, using their respective oxidases to generate hydrogen peroxide. Peroxidase was then used in the oxidative coupling of 4-aminoantipyrine and 2-hydroxy-3,5-dichlorobenzenesulfonate to form the measured chromogen. It may be determined from figure 3 that the slope of the curve for the HDL choline-containing phospholipids assay is nearly twice that of the cholesterol assay, on a molar basis. The increased sensitivity due to the substitution of 2-hydroxy-3,5-dichlorobenzenesulfonate for phenol has also produced an increase in the precision of the HDL choline-containing phospholipids assay. The precision of the HDL choline-containing phosphiolipids assay was checked by assaying several aliquots of various serum pools. On the basis of the data presented in table 1 both the within-run and between-run reproducibility of the proposed procedure was judged to be acceptable.

Tab. 1. Reproducibility of the proposed choline=containing phospholipid procedure.

\begin{tabular}{llllllll}
\hline \multicolumn{2}{l}{ Within-run } & \multicolumn{5}{c}{ Between run } \\
$\mathrm{N}^{\mathrm{a}}$ & $\begin{array}{l}\overline{\mathrm{x}} \\
(\mathrm{mmol} / \mathrm{l})\end{array}$ & $\begin{array}{l}\mathrm{SD} \\
(\mathrm{mmol} / \mathrm{l})\end{array}$ & $\begin{array}{l}\mathrm{CV} \\
(\%)\end{array}$ & $\mathrm{N}$ & $\begin{array}{l}\overline{\mathrm{x}} \\
(\mathrm{mmol} / \mathrm{l})\end{array}$ & $\begin{array}{l}\mathrm{SD} \\
(\mathrm{mm}) \mathrm{l} / \mathrm{l})\end{array}$ & $\begin{array}{l}\mathrm{CV} \\
(\%)\end{array}$ \\
\hline 20 & 0.920 & 0.022 & 2.4 & 20 & 0.990 & 0.046 & 4.6 \\
20 & 1.890 & 0.024 & 1.3 & 20 & 1.94 & 0.081 & 4.2 \\
\hline
\end{tabular}

${ }^{a}$ Where: $N=$ number of tests, $\overline{\mathrm{x}}=$ mean value, $S D=$ standard deviation, and $\mathrm{CV}=$ coefficient of variation.

The determination of the choline-containing phospholipids in the HDL frăction of serum following chemical precipitation of the LDL and VLDL fractions may be considered to be controversial. Switzer \& Eder (21) have reported that lysolecithin comprises $9.6 \%$ of the total phospholipids of serum and that a major portion of this phospholipid is associated with albumin and thus would not be precipitated with the LDL and VLDL molecules. However, in a more recent review (22) no mention of this phenomenon was made but rather it wass stated that all of the lipids, apart from the free fatty acids, were carried in the plasma as lipoprotein complexes. As well, recent studies that have compared chemical fractionation to electrophoresis (1) and ultracentrifugation $(11,23)$ have reported good correlation between the techniques and have made no mention of an albumin-lysolecithin complex. More recently, Wille (24) reported that there is an albuminapolipoprotein A-I complex in serum which is able to bind lysolecithin. This complex has an electrophoretic mobility similar to albumin and appears in the $\mathrm{d}>1.21 \mathrm{~kg} / 1$ (VHDL) fraction obtained by ultracentrifugation. Further, this complex is able to bind more lysolecithin than albumin can alone. Since this complex contains apolipoprotein A-I, which apparently binds most of the lysolecithin in the complex; it seems reasonable to include the lysolecithin of this complex in the determination of HDL choline-containing phospholipids. Therefore, on the basis of this report, the above mentioned comparative studies $(1,11,23)$ and the inherent ease and convenience of chemical fractionation we chose to adopt the method. 
The combination of magnesium acetate and dextran sulfate 500 was chosen as the precipitating agents for the HDL choline-containing phospholipid assay due to their previous use in the determination of HDL cholesterol (14). It was shown in this previous report that magnesium/dextran sulfate 500 did not interfere in the enzymatic determination of HDL cholesterol. In a subsequent paper (16), magnesium/dextran sulfate 500 was compared with magnesium/phosphotungstate, manganese/heparin and polyethylene glycol 6000 for possible interference with the determination of cholesterol and was found not to interfere. Since the $\mathrm{HDL}$ choline-containing phospholipid assay involves a different enzymic sequence under different reaction conditions, it seemed necessary to repeat the interference study with the magnesium/dextran sulfate reagents. This was done by comparing the performance of the normal reagent with that of a reagent contaminated with magnesium/dextran sulfate 500 . The contaminated reagent was prepared to contain magnesium/dextran sulfate 500 to the concentration that would be present if $10 \mu \mathrm{l}$ of an HDL fraction had been added to $1.0 \mathrm{ml}$ of reagent. A series of spectra obtained using the contaminated and the uncontaminated reagents with lecithin standards are shown in figure 4. Our previous study (16) indicated that the precipitating agents do not cause any measurement problems if the reactions are carried out at $37^{\circ} \mathrm{C}$ as described under procedure. There

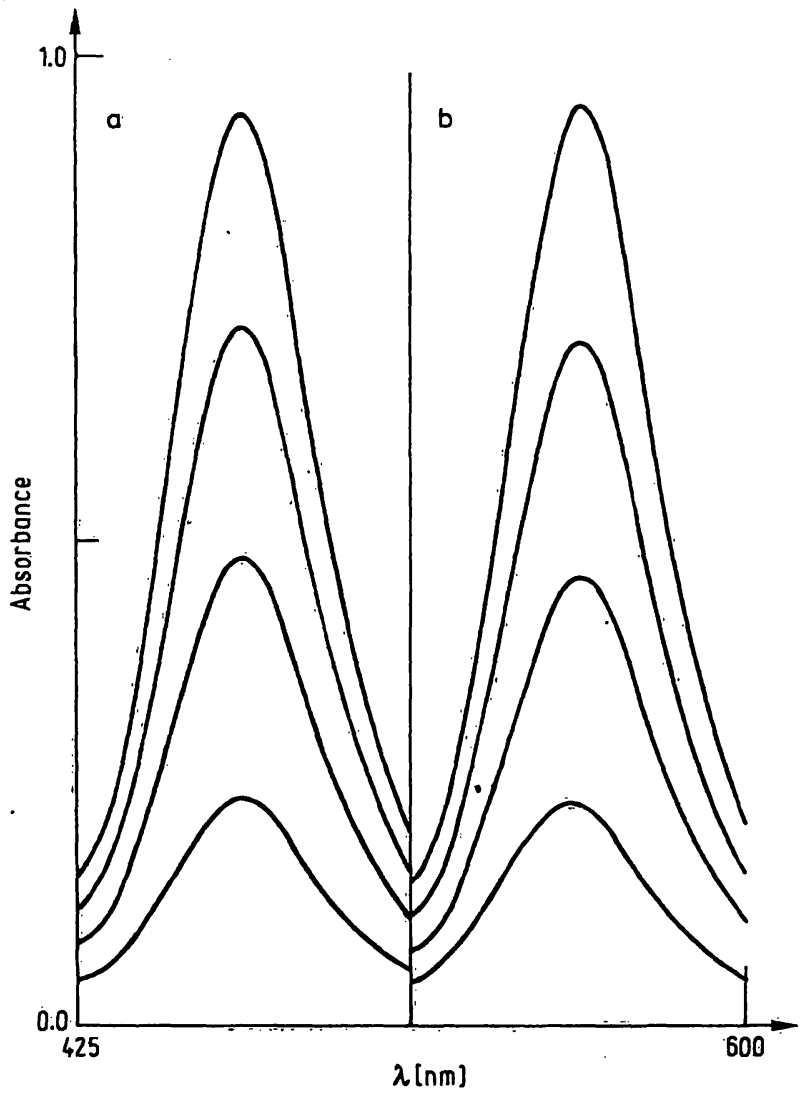

Fig. 4. Shown are the comparative spectra for the cholinecontaining phospholipid assay, over the concentration range of $0.5-2.0 \mathrm{mmol} / 1$, in the presence (a) and absence (b) of the precipitating reagents magnesium acetate and dextran sulfate 500 . appears to be no consistent difference between the spectra obtained with the contamined reagent and the spectra obtained with the uncontaminated reagent. The spectra are intended to show the lack of any obvious interference due to the magnesium/dextran sulfate. The small difference between contaminated and uncontaminated spectra are probably due to the experimental error, in that repeated studies in which single wavelength measurements at $510 \mathrm{~nm}$ were made failed to reveal an interference.

There has been a great interest in the determination of serum HDL cholesterol levels due to its proposed involvement in the atherosclerotic process. The HDL molecule has been postulated to pick up cholesterol from peripheral tissues for transfer to other lipoproteins or for transport to the liver for disposal (25). This removal of cholesterol is also proposed to involve the enzyme lecithin: cholesterol acyltransferase which is activated by apolipoprotein A-I of the HDL molecule. The esterification of cholesterol by the transfer of a fatty acid from lecithin is catalyzed by lecithin: cholesterol.acyltransferase (25). However, it is not yet known whether or not this proposed role of HDL is the mechanism for its protective nature. Since at least part of the role of phospholipids in the serum lipoproteins is to allow the lipoproteins to carry the neutral lipids, it would seem to be reasonable that one might expect to find a correlation between HDL cholesterol and HDL choline=containing phospholipids. For this reason, and as a possible application of this method, we obtained 55 serum samples whose total cholesterol levels ranged from 82 to $437 \mathrm{mg} / \mathrm{dl}(2.1-11.3 \mathrm{mmol} / \mathrm{l})$ and determined their levels of HDL cholesterol and HDL cholinecontaining phospholipids. A plot of HDL cholesterol vs HDL choline-containing phospholipids is shown in figure 5 . There appears to be a linear relationship be-

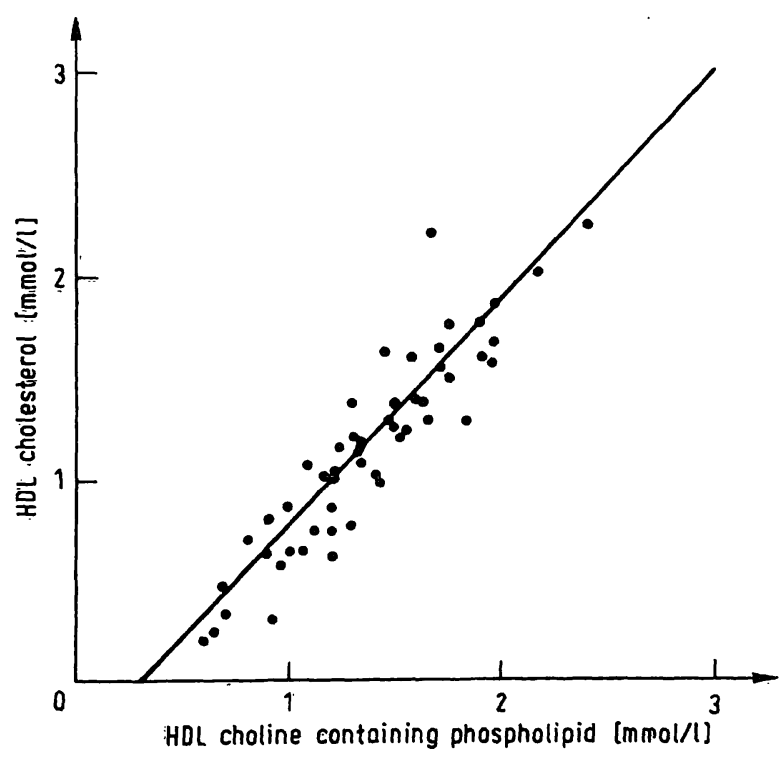

Fig. 5. Plotted is the correlation between HDL-cholesterol and HDL-choline-containing phospholipid concentrations. $\mathrm{N}=55 ; \mathrm{r}=0.913 ; \mathrm{y}=1.12 x-0.34$. 
tween the two, as evidenced by the coefficient of correlation of 0.913 . As well, it may be noted that there is a negative intercept suggesting that there may be measurable amounts of phospholipids present when there is no detectable cholesterol. This preliminary data appears to correlate well with the work of previous investigators $(3,9,11-13,23)$. Although comparison of the HDL phospholipid concentrations is difficult, due to the use of units based on a weight per unit volume rather than a moles per liter system, it would appear that our mean value of $1.368 \mathrm{mmol} / 1 \mathrm{HDL}$ choline-containing phospholipid falls in the middle of the apparent range of mean values of $0.570-1.834 \mathrm{mmol} / 1$ that we calculated from previous reports $(3,9,11-13,23)$. In addition, the good correlation obtained between HDL cholesterol and choline-containing phospholipids, demonstrated in figure $5(r=0.913)$ is consistent with the previous studies of the investigators on this controversial issue $(11-13,23)$. The determination of HDL choline-containing phospholipids may prove to be useful in the investigation of the atherosclerotic process. The described procedure would appear to be more convenient than the traditional method (26) and more sensitive and re-

producible than the previous enzymic procedure $(8,11)$.

\section{References}

1. Mistilis, S. P., Goren, R., Tall, A. R. \& Hickie, J. R. (1975) Aust. N. Z. J. Med. 5, 540-3.

2. Lee, L. M. Y. (1975) Clin. Chim. Acta 32, 25-32.

3. Kajiyama, G., Nakagawa, M., Takata, K., Nakao, S. \& Miyoshi, A. (1981) Hiroshima J. Med. Sci. 30, 175-182.

4. Gillett, M. P. T. \& Besterman, E. M. M. (1975) Artherosclerosis 22, 111-124.

5. Gordon, T., Castelli, W. P., Hjortland, M. C., Kannel, W. B. \& Dawber, T. R. (1977) The Framingham Study. Am. Journ. Med. 62, 707-714.

6. Scanu, A., Lump, E., Tota, J., Koga, S., Stiller, E. \& Albers, L. (1970) Biochemistry 9, 1327-1335.

7. Sodhi, H. S. \& Gould, R. G. (1976) J. Biol. Chem. 242, $1205-1210$.

8. Takayama, M., Itoh, S., Nagasaki, T. \& Tanimizu, I. (1977) Clin. Chim. Acta 79, 93-98.

9. Bloom, R. J. \& Elwood, J. C. (1981) Clin. Biochem. 14, 119-125.

10. Christian, J. C., Kang, K. W. \& Poon, Y. C. (1981) Clin. Chim. Acta 21, 289-290.

11. Yamaguchi, Y. (1980) Clin. Chem. 26, 1275-1277.

12. Rubiés-Prat, J., Masdew, S., Nubiola, A. R., Chacón, P., Holguera, C. \& Masana, L. (1982) Clin. Chem. 28, 525-527.

13. Telesforo, P., Salino, L. \& D'Errico, A. (1981) Clin. Chem. $27,354-355$.
14. Artiss, J. D., McGowan, M. W. \& Zak, B. (1981) Microchem. J. 26, 198-209.

15. Artiss, J. D., Draisey, T. F., Thibert, R. J., Zak, B. \& Taylor, K. E. (1980) Microchem. J. 25, 153-1.68.

16. McGowan, M. W., Artiss, J. D. \& Zak, B. Microchem. J. (in press).

17. Artiss, J. D., Draisey, T. F., Thibert, R. J. \& Taylor, K. E. (1979) Microchem. J. 24, 239-258.

18. Kostner, G. M. (1976) Clin. Chem. 22, 695.

19. Imamura, S. \& Horiuti, Y. (1979) J. Biochem. Tokyo 85, 79-95.

20. Ikuta, S., Imamura, S., Misaki, H. \& Horiuti, Y. (1977) J. Biochem. Tokyo 82, 1741-1749.

21. Switzer, S. \& Eder, H. A. (1965) J. Lipid Res. 6, 506-511.

22. Jackson, R. L. \& Gotto, A. M. (1974) New Eng. J. Med. 290, 87-93.

23. Schwandt, P. \& Weisweiler, P. (1979) Clin. Chim. Acta 95, 395-399.

24. Wille, L. E., Heiberg, A. \& GJone, E. (1978) Scand. J. Clin. Lab. Invest. 38, Suppl. 150, 59-65.

25. Glomset, J. A. (1968) J. Lipid Res. 9, 155-167.

26. Zilversmit, D. B. \& Davis, A. K. (1950) J. Lab. Clin. Med. $35,155-160$.
Joseph D. Artiss, Ph. D. Department of Pathology Wayne State University 540 East Canfield Detroit, Michigan 48201 U.S.A. 